\title{
Fibrous Dysplasia: Clinicopathologic Presentation of 36 Cases
}

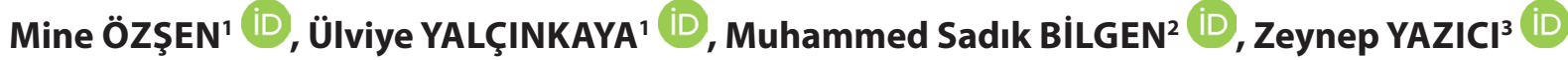

Department of 'Surgical Pathology, ${ }^{2}$ Orthopedics, and ${ }^{3}$ Radiology, Uludag University Faculty of Medicine, BURSA, TURKEY

This study was presented as a poster at the 26th National Pathology Congress and 7th National Cytopathology Congress, Antalya on November 2-6, 2016.

\section{ABSTRACT}

Objective: Fibrous dysplasia is a slowly progressing bone lesion resulting from displacement of the normal medullary bone with abnormal fibroosseous tissue. The aim of this study was to assess the similarities and differences of our cases in relation to published reports.

Material and Method: In this study, the archives of the Uludag University Medical Faculty Department of Pathology were screened for fibrous dysplasia cases between 2004 and 2016.

Results: Within the mentioned period, there were 36 cases diagnosed as fibrous dysplasia. There were 21 male, and 15 female cases with an average age of $27.8 \pm 14.8$ years (range 7-79 years). The most frequently affected sites were femur, costae, and craniofacial bones. There was one case localized to metacarpal bone, a very rare affection site. There were 4 polyostotic cases including 2 cases of McCune-Albright syndrome. Pelvic bone was affected in the polyostotic type, similar to published reports. Unlike former reports, however, long tubular bones were affected in male patients in our series. In our series, 32 cases had classical fibrous dysplasia, 3 cases had fibrocartilaginous, and one case had fibroosseous variants. Four cases localized to costae were accompanied by aneurysmal bone cyst. The presenting symptom was pathological fractures in a total of 4 cases, 3 localized to the femur, and 1 to the costa. Recurrence occurred in 5 cases treated with curettage. Two of the monostotic fibrous dysplasia cases developed malignant transformation into osteosarcoma.

Conclusion: We conclude that our series of fibrous dysplasia cases have slight differences and mainly similar characteristics with the series reported earlier, when all features are taken into consideration.

Key Words: Fibrous dysplasia, Bone, McCune-Albright syndrome

\section{INTRODUCTION}

Fibrous dysplasia (FD) was first defined as an anomalous dysplastic development of the bone in 1938. The etiology of this slow developing lesion with displacement of normal medullary bone with abnormal fibroosseous tissue, however, is not clear yet (1-3). A possible mechanism may be the polyzygotic activated mutation of GNAS1 gene localized at 20q13 chromosome within somatic cells during embryogenesis $(4,5)$. FD may present as either monostotic (i.e. effecting a single bone), or polyostotic (i.e. effecting multiple bones) in the clinical setting. The polyostotic form may be accompanied by various endocrine disorders as in McCune-Albright syndrome (1). Prognosis of FD is usually good and biological behavior of the tumor is unrelated to localization. Local recurrence may occur following inadequate surgical therapy. FD localized to long bones is easy to diagnose in light of adequate clinical and radiological information and typical microscopical findings. Histopathological findings of FD localized to

(Turk Patoloji Derg 2018, 34:234-241)

Received : 17.09.2017 Accepted : 27.03.2018 craniofacial bones, however, are more challenging and complex (1-3).

The aim of this study was to report clinicopathological properties of our series, and to assess the similarities and differences between our findings and former reports concerning this developmental disorder presenting with various forms and predilection sites.

\section{MATERIALS and METHODS}

In this study, the archives of the Uludag University Medical Faculty Department of Pathology were screened for FD cases between 2004 and 2016. The hematoxylin-eosin stained slides were re-evaluated and the histopathologic findings were noted. The cases were summarized according to age, gender, site, and clinicopathological properties in a retrospective setting. Special attention was paid to tumors of craniofacial bones, costae, long bones, and flat bones and their clinicopathological findings.

Correspondence: Mine ÖZŞEN

Uludag University Faculty of Medicine,

Department of Surgical Pathology, BURSA, TURKEY

E-mail: m.isikoglu@hotmail.com Phone: +90 2242953680 


\section{RESULTS}

Within the mentioned period, there were 36 cases diagnosed as FD (Table I). There were 21 male (58.4\%), and 15 female (41.6\%) cases with an average age of $27.8 \pm 14.8$ years (range 7-79 years). FD was diagnosed at a total of 39 different sites in these 36 cases including 15 femur (38.4\%), 9 costae (23\%), and 9 craniofacial bone (23\%). Of all cases, 4 were polyostotic (11.1\%). All pelvic bone tumors were of polyostotic form. Ten of the 16 cases with long tubular bone tumors were male.
The presenting complaint was pain in $17(47.2 \%)$, and localized swelling in 9 (25\%) of the cases. Clinically pathological bone fractures were encountered in 4 (11.1\%) cases. Three of these cases were localized to femur, and the remaining 1 case was localized to costa. Two cases were under surveillance for McCune-Albright syndrome. The first case was a 13-year-old female patient presenting café au lait spots, osteoporosis, and hyperandrogenism. Her 3 siblings had similar symptoms. The case was diagnosed as FD following curettage of the lytic lesion localized in her right femur, expressing benign features. Detailed

Table I: Clinicopathological findings of cases $(n=36)$

\begin{tabular}{|c|c|c|}
\hline Variable & & No. of cases \\
\hline \multirow[t]{2}{*}{ Gender } & Female & 15 \\
\hline & Male & 21 \\
\hline \multirow[t]{3}{*}{ Age } & $\leq 20$ & 11 \\
\hline & $20-40$ & 20 \\
\hline & $\geq 40$ & 5 \\
\hline \multirow[t]{3}{*}{ Type } & Monostotic & 32 \\
\hline & Polyostotic & 4 \\
\hline & McCune-Albright syndrome & 2 \\
\hline \multirow{11}{*}{ Tumor site } & Femur & 15 \\
\hline & Rib & 9 \\
\hline & Craniofacial bones & 9 \\
\hline & Pelvic bones & 2 \\
\hline & Humerus & 1 \\
\hline & Ulna & 1 \\
\hline & Calcaneus & 1 \\
\hline & Tibia & 1 \\
\hline & Fibula & 1 \\
\hline & Short bones & 1 \\
\hline & Metacarpal bone & 1 \\
\hline \multirow[t]{3}{*}{ Histological Variant } & Classical fibrous dysplasia & 32 \\
\hline & Fibrocartilaginous dysplasia & 3 \\
\hline & Fibroosseous dysplasia & 1 \\
\hline \multirow[t]{2}{*}{ Secondary aneurysmal bone cyst } & Yes & 4 \\
\hline & No & 32 \\
\hline \multirow[t]{2}{*}{ Pathological fracture } & Yes & 4 \\
\hline & No & 32 \\
\hline \multirow[t]{2}{*}{ Surgery } & Curettage & 18 \\
\hline & Resection & 8 \\
\hline \multirow[t]{2}{*}{ Recurrence } & Yes & 5 \\
\hline & No & 31 \\
\hline \multirow[t]{2}{*}{ Malignant transformation } & Yes & 2 \\
\hline & No & 34 \\
\hline
\end{tabular}


radiological examination revealed multiple lesions in the maxilla and craniofacial bones. The second case was a 7-year-old female patient. She also had café au lait spots and anomalous secondary sexual development. She presented with walking disorder following a trauma, and had a pathological fracture in left femur and multiple bone lesions. She was diagnosed as FD following curettage and bone grafting. She had lesions in skull bones, both lower limbs, both hands and feet, metacarpal and carpal bones, tarsal bones, and pelvis.

Radiological images of 12 cases were obtained from the archive. All had expansile yet non-destructing mass lesions appearing as ground glass density, benign in nature (Figure 1A-D).

Histopathologically 32 cases were classical FDs. Microscopically they show fold of irregular, anastomosing immature bone trabeculae scattered within a fibrous tissue without cytological atypia. There were no osteoblastic cell surrounding this areas expressing metaplastic woven bone features. In 3 cases due to benign cartilage nodules and enchondral ossification accompanying classical FD appearance the diagnosis was fibrocartilaginous dysplasia. All of these cases were localized in femur and two were of polyostotic form. An 8-year-old male patient had a metacarpal lesion localized at the third metacarpal bone in his left hand showing psammoma-like cementoid bodies and was diagnosed as fibroosseous dysplasia. In four cases there were aneurysmal bone cysts all localized in costae (Figure 2A-D).

The first line of treatment consisted of curettage and bone grafting in $18(50 \%)$, radical resection in $8(22.2 \%)$, and surveillance following biopsy in 7 (19.4\%) of the cases. No problems were encountered during surveillance of these 7 cases. Three cases were referred to our department for consultation from other centers.

In five of the cases, recurrence was found (13.8\%). Treatment of recurrence was curettage in all cases (Table II).

In two cases (5.5\%), malignant transformation into osteosarcoma was seen 9 months and 5 years following initial diagnosis and treatment, and both were monostotic FD (Figure 3A-D). These cases did not receive radiation therapy. One of the cases was a 29 -year-old male with a

Table II: Clinical data of recurrent cases

\begin{tabular}{ccccccccc}
\hline Case & Age & Sex & Site & $\begin{array}{c}\text { First surgical } \\
\text { procedure }\end{array}$ & $\begin{array}{c}\text { Number of } \\
\text { recurrences }\end{array}$ & $\begin{array}{c}\text { Time to first } \\
\text { recurrence }\end{array}$ & $\begin{array}{c}\text { Final surgical } \\
\text { procedure }\end{array}$ & $\begin{array}{c}\text { Postrecurrent } \\
\text { follow-up (months) }\end{array}$ \\
\hline 1 & 11 & M & Femur & Curettage & 1 & 2 years later & Osteotomy & 50 \\
\hline 2 & 7 & M & Femur & Curettage & 1 & 4 years later & Curettage & 12 \\
\hline 3 & 25 & F & Mandible & Curettage & 1 & 7 years later & Curettage & - \\
\hline 4 & 31 & M & Calcaneus & Curettage & 1 & 3 years later & $\begin{array}{c}\text { Curettage and bone } \\
\text { grafting }\end{array}$ & - \\
\hline 5 & 32 & M & Maxilla & Curettage & 1 & 3 years later & Wide resection & 3 \\
\hline
\end{tabular}

M: Male, F: Female.
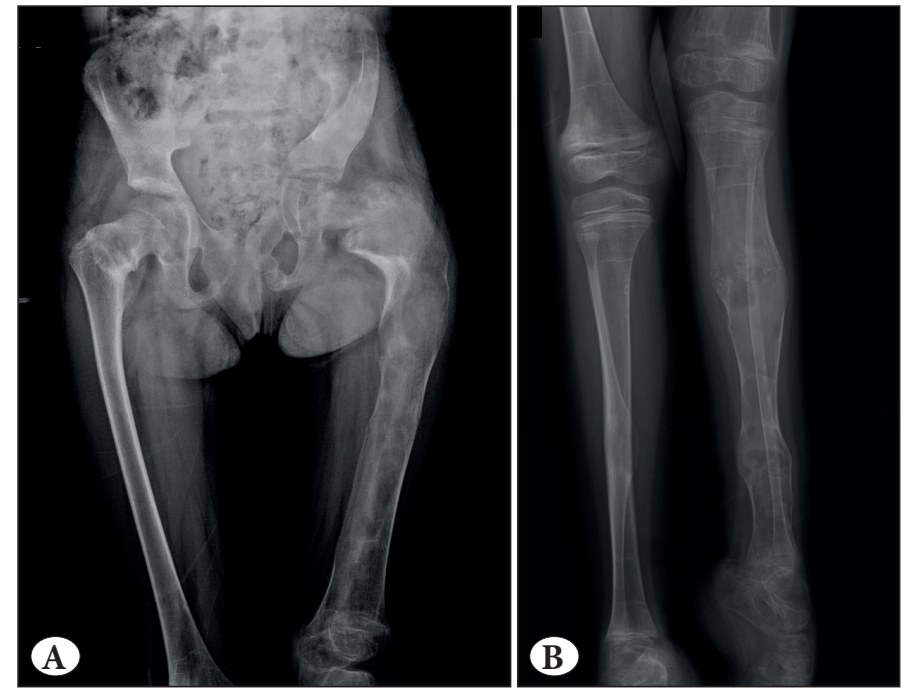

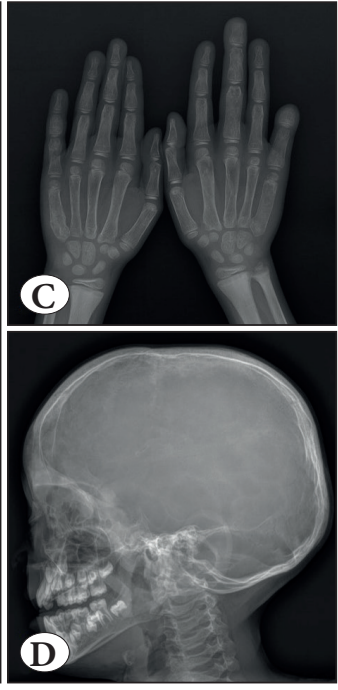

Figure 1: A-C) Frontal radiograph of the thighs shows bilateral coxa vara angulation of the proximal femurs (shepherd's crook deformity). Bones are abnormal with mixed sclerosis and lucency and remodeling, which is particularly evident at the left femur and tibia and some phalanges and metacarpals. D) Lateral radiograph of the skull demonstrates thickening and sclerosis of the frontal calvarium. 
lesion localized in the distal portion of right femur. This patient underwent resection at the distal femur level, and was scheduled for chemotherapy. Unfortunately the patient passed away 5 months following malignant transformation due to disseminated lung metastases. The other case was a 42-year-old female with a lesion localized in the distal portion of right humerus. She suffered from a swelling at her right elbow for two years. Radiological examination revealed an expansile, well circumscribed, radiolucent lesion. Tru-cut biopsy of the lesion revealed FD. The lesion started to grow 9 months following initial diagnosis leading to destruction in the cortical portion of the bone. She underwent resection at the distal humerus level. The specimen was diagnosed as low grade osteosarcoma. In order to exclude the differential diagnosis of FD like osteosarcoma since the beginning, immunohistochemical staining of the initial slides with CDK4 and MDM2 had negative results. Ki67 proliferative index was high in the resection specimen unlike the initial biopsy (Figure 4A, B). Re-evaluation of the initial radiological images revealed no features suggesting malignancy. The medullary tip and the surrounding surgical margins were intact. She is still alive and under surveillance.

\section{DISCUSSION}

The real incidence of FD is hard to determine due to asymptomatic cases. Yet, it is well accepted that this clinical entity compromises $5-7 \%$ of all primary bone tumors $(6,7)$.

The two genders are affected equally, and the peak incidence is in adolescents and young adults (1-3). Our series included mostly young male cases.
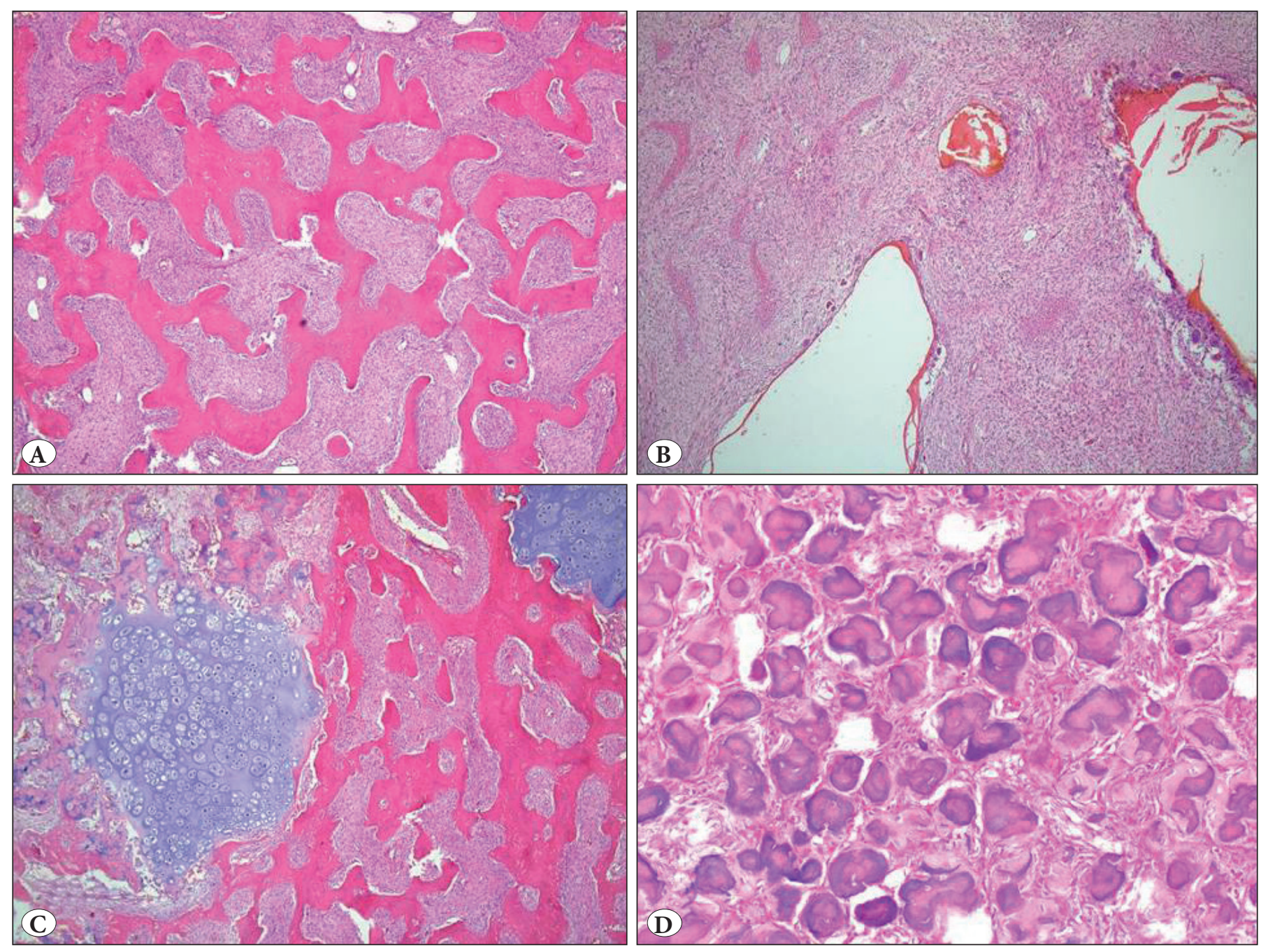

Figure 2: A) Typical low-power appearance of fibrous dysplasia. The lesion contains branching and anastomosing, circular and irregular immature bone trabeculae (Chinese letters) scattered within a fibrous tissue (H\&E; x40). B) Secondary aneurysmal bone cyst areas with fibrous dysplasia (H\&E; x40). C) Fibrocartilaginous dysplasia, broad islands of cartilage (H\&E; x40). D) Fibroosseous dysplasia, the tumor produces spherical masses of osteoid (H\&E; $\mathrm{x} 40)$. 
Although FD may affect simply every bone in the skeleton, femur, costae, and the craniofacial region are more frequently involved (8). Vertebrae, pelvic bones, radius, fibula, and short tubular bones of hand and foot are rarely affected $(2,6,8)$. Metacarpal involvement is extremely rare and is reported as sporadic cases only (9). In a multi-central clinicopathological study supported by the European Pediatric Orthopedic Society, the femur was the most frequent site of the lesion, followed by the tibia. Fourteen cases out of 23 monostotic FD, 9 cases out of 10 polyostotic FD, and all 20 cases with McCune-Albright syndrome had lesions localized in the femur (10). In our series, the femur was involved in 15 out of 36 cases, followed by the craniofacial bones and costae. There was one case with metacarpal involvement, and in a case with McCuneAlbright syndrome the short tubular bones in both hands and feet are involved. In a report from the Mayo Clinic, jaw, the long bones and flat bones are mainly involved in female patients, whereas the costae and cranial bones are mainly involved in the male (2). In our series, male cases had mainly long tubular bone involvement.

FD may be divided into two somewhat overlapping forms as monostotic, and polyostotic. The former has an incidence of $70-80 \%$, while the latter may be seen as frequent as 20 $30 \%(1-3)$. In our series, four cases (25\%) were polyostotic. Craniofacial bones and especially the maxilla, costae, and long bones are frequently affected in the monostotic form. Pelvic bones and scapula are frequently affected
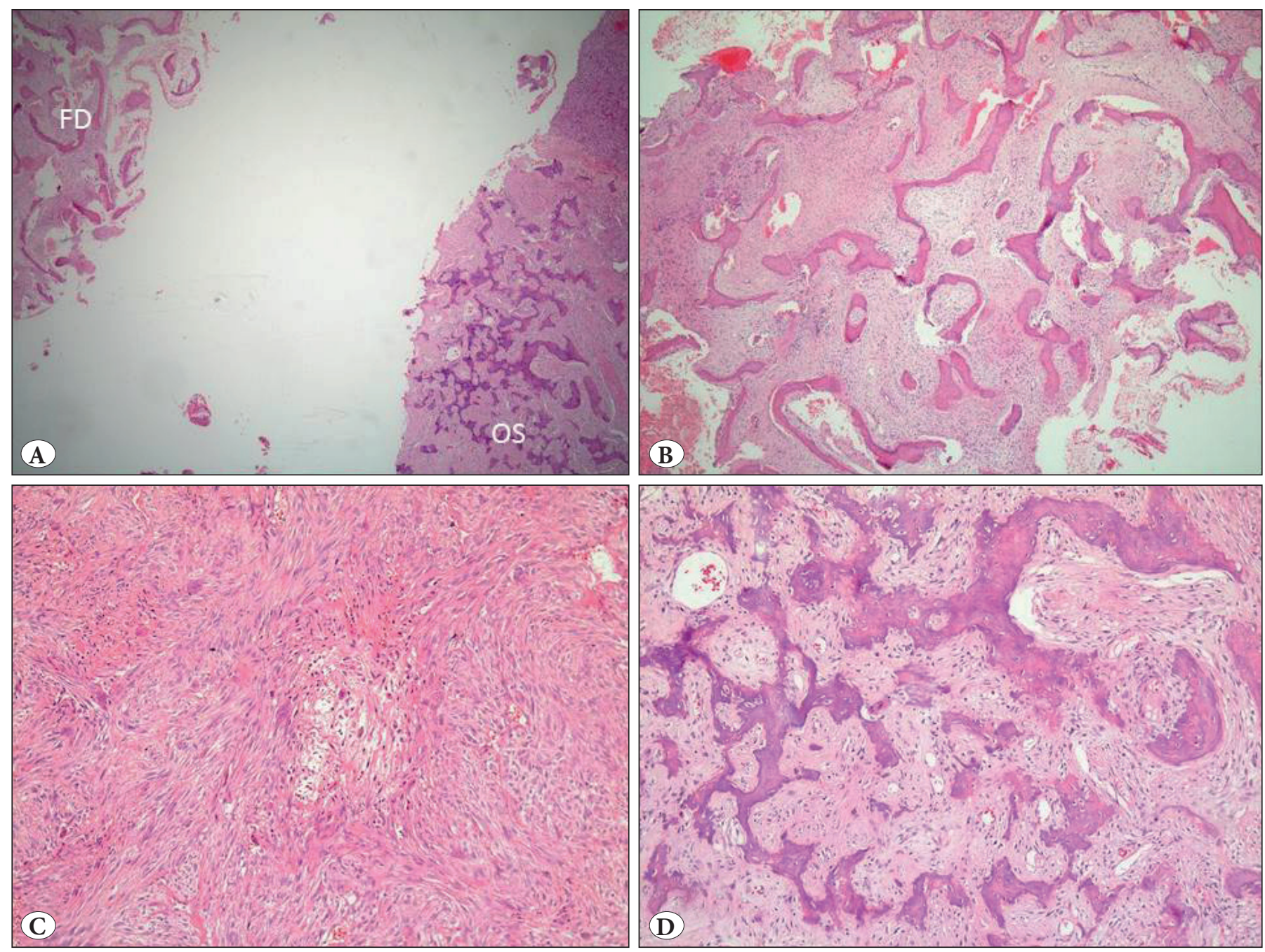

Figure 3: A) Malignant transformation of fibrous dysplasia, fibrous dysplasia areas (FD) and osteosarcomatous areas (OS) (H\&E; x10). B) Areas of fibrous dysplasia; curvilinear trabeculae of metaplastic woven bone in hypocellular, fibroblastic stroma (H\&E; 40 ). C) Areas of sarcoma contains malignant spindle cells arranged in intersecting fascicles and there are foci of necrosis (H\&E; 40 ). D) Osteosarcomatous areas composed of mineralized neoplastic bone and tumor cells. The tumor cells show moderate cytological atypia (H\&E; $\mathrm{x} 40$ ). 

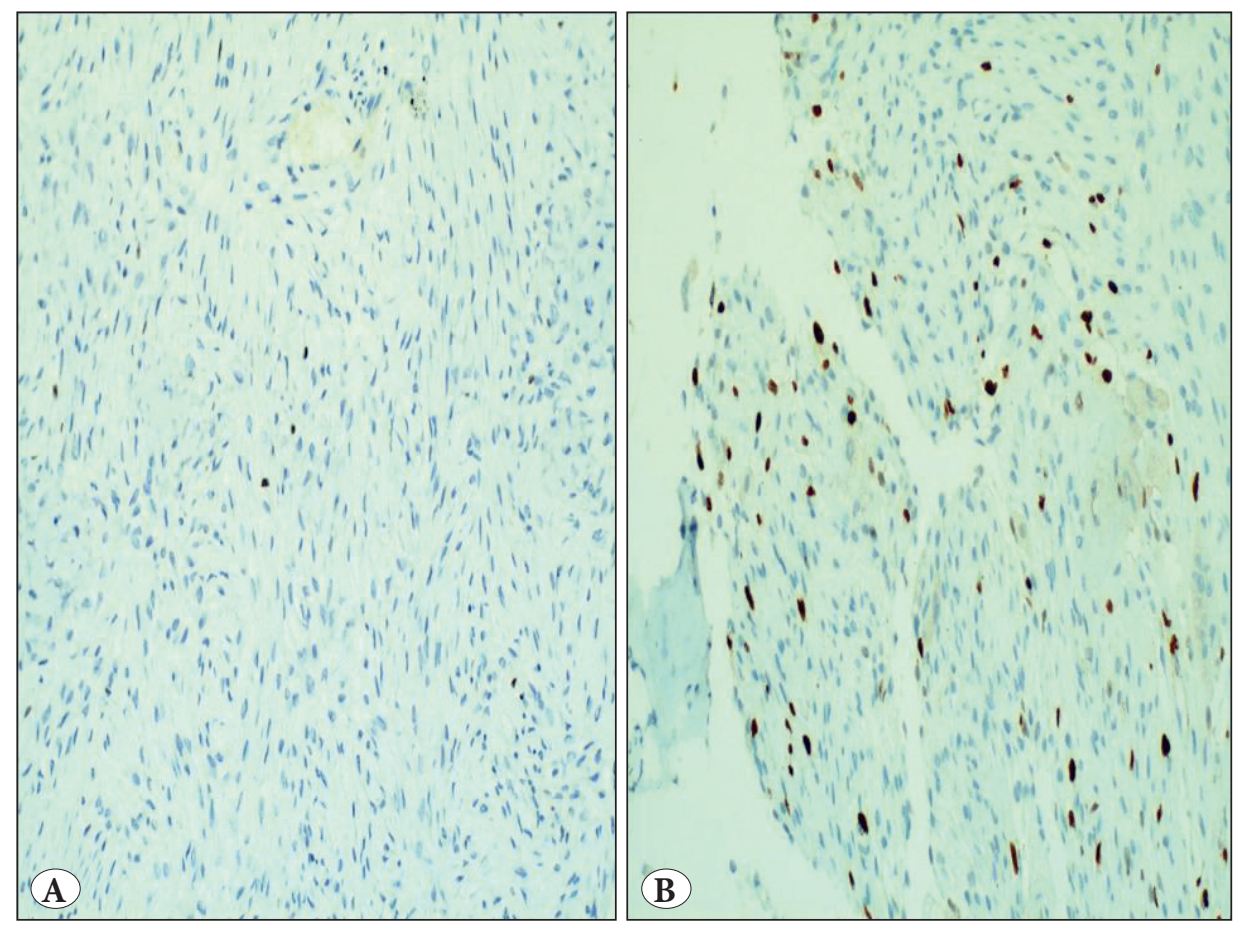

Figure 4: A) Low Ki67 proliferative index in the initial biopsy material in the case presented with malignant transformation (IHC; x200). B) High Ki67 proliferative index in osteosarcomatous areas in the resection material (IHC; x200).

in the polyostotic form (1-3). In our series, pelvic bone involvement was found in polyostotic FD cases.

The most frequent presenting complaint is pain, followed by swelling, and pathological bone fractures. The complaints depend on the age, site, accompanying lesion, and endocrine disorder (5). In a study by Chapurlat et al, the authors reported that pain was more frequent among adult patients than children; $67 \%$ of the patients suffered from pain at the involvement site (11). The monostotic form is usually asymptomatic, whereas the polyostotic form leads to deformation in craniofacial bones and femur (i.e. the shepherd's crook), and fractures. Pathological fractures and bending is frequent in load bearing bones. Polyostotic FD accompanied by various endocrine disorders, irregular skin pigmentation, and early sexual maturity is called McCune-Albright syndrome. Another syndrome is called Mazabraud syndrome in which FD is accompanied by intramuscular myxoma $(1-3,12)$. In our series, the most frequent complaint was pain as well. This complaint was followed by swelling and pathological bone fractures. Of the four cases with pathological fractures, 3 had lesions in the femur, the other was localized in the costa.

Radiologically FD presents as an expansile, intramedullar lesion with ground glass appearance within a well circumscribed cortical contour (13). Secondary changes such as cyst formation or fractures may be present. Sometimes punctate or focal calcification may indicate cartilage differentiation, and this form is called fibrocartilaginous dysplasia (1). We were able to find radiological images of only 12 cases from the archive, and all had expansile and non-destructing mass lesions showing ground glass density.

Microscopically the tumor presents narrow, circular and usually shaped as a fish hook, irregular, immature bone trabeculae scattered within a fibrous tissue showing various degrees of cellularity. This net-like bone is found in various amounts and shape and resembles the Chinese letters. These trabeculae are not surrounded by osteoblasts, and thus they do not evolve into mature bone. The number, distribution and maturity of bone trabeculae differ from area to area and case to case. Mature lamellar bone trabeculae may be present in FD cases particularly localized in the jaw. In cases with pathological bone fracture or recurrence following initial interventions, osteoblasts may be present surrounding the reactive bone trabeculae, as well. In some instances, bone formation may be prominent. In the fibrocartilaginous type, benign chondral nodules and enchondral ossification may be present. Focal cementoid bodies may be found in lesions localized in skull bones. Such lesions are called fibroosseous dysplasia and may be mistaken for meningiomas. Aneurysmal bone cyst formation-like cystic degeneration, hemorrhage, and foamy histiocytes may be present in some cases. Sometimes intralesional hemorrhage may lead to osteoclastic reactions. And finally, there may be diffuse myxoid degeneration in the fibrous stroma. All these secondary changes are usually seen in lesions present 
for a long time $(1-3,13,14)$. In our series, 4 cases had secondary aneurysmal bone cyst, all localized in costae. One case localized in the costa showed diffuse myxoid degeneration, and a case localized in the metacarpal bone presented with cementoid bodies. There were 3 cases of fibrocartilaginous FD involving the femur, 2 polyostotic and one in monostotic form.

Malignant transformation is reported in $0.4-6.7 \%$ of FD cases in the literature. Such transformation may lead to osteosarcoma, chondrosarcoma, and fibrosarcoma formation and is more frequent in the polyostotic form. Radiation therapy has an accepted effect on malignant transformation (15-17). In our series two cases presented with malignant transformation into osteosarcoma, one after 9 months and the other 5 years following the diagnosis. They were both monostotic, and had no former history of radiation therapy.

The differential diagnosis of FD includes various entities such as osteofibrous dysplasia, non-ossifying fibroma when excessive foamy histiocytes are present, desmoplastic fibroma when a fibrous component is prominent, healing fracture, Paget's disease, low grade osteosarcoma resembling fibrous dysplasia, enchondroma when the chondroid component is prominent, and growth plate. The enchondral ossification surrounding the cartilaginous islands in fibrocartilaginous dysplasia is disorganized unlike the growth plate. There are typical FD areas among these cartilaginous islands. Presence of fracture may lead to misdiagnosis, but typical FD areas along with areas of enchondral ossification and organization of osteoblasts around lamellar bone trabeculae are of help in the diagnosis. Osteofibrous dysplasia is localized in the cortex unlike FD. The fibrous stroma presents a storiform pattern with osteoblasts surrounding bone trabeculae and single epithelial cells positive for cytokeratin. There is a zonal structure where the periphery of the lesion is more mature with mineralized bone trabeculae. The most important differential diagnosis is with low grade osteosarcoma. Hypercellularity, nuclear atypia and pleomorphism, increased mitotic activity, and high Ki67 proliferative index suggest malignancy. The absolute indicators of malignancy include permeative growth between the cortical/spongy bone trabeculae, infiltration, and presence of soft tissue involvement (1-3, 6). Immunostaining with MDM2 and CDK4 is also of help in distinguishing low grade sarcoma from benign fibroosseous lesions. The sensitivity of these markers are reported to be $89-100 \%$, and the selectivity may be between $97.5-100 \%(18,19)$. We performed MDM2 and CDK4 immunostaining in 6 of our cases with hypercellularity and slight pleomorphism with negative results. In these cases the Ki67 proliferative indices were low, as well.
Prognosis is well in FD, and is generally unrelated to biological behavior and anatomic site. Yet, it may lead to deformities and uneven extremities, affect cranial nerves, and polyostotic form may even cause paralysis. Malignant transformation into sarcoma indicates poor prognosis, and lung metastases are frequent $(1,15-21)$.

FD is usually diagnosed based upon radiological images, and biopsy is unnecessary in typical cases. The best treatment in asymptomatic and undeformed cases is surveillance. In polyostotic cases and when surgical treatment is not proper, medical treatment is advised to end the pain, stabilizing the lesion, and support bone structure to avoid fractures. Bisphosphonates are preferred in such treatments at various dosages (21). Surgical therapy is preferred in treating deformities, to avoid pathological fractures, and treating symptomatic lesions. Treatment options include radical resection, conservative local resection, or curettage. Sometimes internal fixation may be needed while treating deformities $(20,22,23)$. Pathological fractures may be treated with curettage and bone cement installation. Many suggest that bone cement is a temporary solution and that bone grafting should be preferred especially in children. Consequently the graft may be removed by the tumor and the tumor may recur. This resorption is infrequent in the adult cases. The growth of lesions in FD are expected to slow down following puberty. Yet in craniofacial bones growth may speed up secondary to aneurysmal bone cyst and biopsy in this period. The growth hormone excreted in McCune-Albright syndrome may also lead to growth of the lesions. Thus, surgical procedures are better performed after puberty if not vital (20-23). Li et al. reported that surgical therapy should be combined with medical therapy in pediatric patients with monostotic type FD involving immature skeletal structures (22). Incomplete resections lead to recurrence in especially aggressive tumors (20). Recently, the GNAS gene mutation has been reported to be positive in $93 \%$ of all FD cases. The possible mechanism of FD depends on the polyzygotic activation mutation of GNAS1 gene in somatic cells. There is also a relationship between inadequate curettage and recurrence. This may be due to the fact that all mutant cells cannot be removed with curettage. Radical excision should be preferred in order to avoid recurrence (20-23). In our series, 16 cases underwent curettage and bone grafting, and 6 had radical resection. All 5 recurrences were seen following curettage.

FD is a rare bone tumor, caused by interruption of regular bone growth, and is usually benign in nature. Proper diagnosis and personalized treatment planning may prevent recurrence and malignant transformation. 


\section{CONFLICT of INTEREST}

The authors declare no conflict of interest.

\section{REFERENCES}

1. Fletcher CDM, Bridge JA, Hogendoorn P, Mertens F. World Health Organization Classification of Tumours of Soft Tissue and Bone: Fibrous dysplasia. 4th ed. Lyon: IARC Press; 2013:352-3.

2. Unni KK, Inwards CY. Dahlin's bone tumors: General aspects and data on 11087 cases. $6^{\text {th }}$ ed. Philadelphia: Lippincott Williams \& Williams; 2010:310-6.

3. Dicaprio MR, Enneking WF. Fibrous dysplasia pathophysiology, evaluation, and treatment. J Bone Joint Surg Am. 2005;87:184864.

4. Bianco P, Riminucci M, Majolagbe A, Kuznetsov SA, Collins MT, Mankani MH, Corsi A, Bone HG, Wientroub S, Spiegel AM, Fisher LW, Robey PG. Mutations of the GNAS1 gene, stromal cell dysfunction, and osteomalacic changes in non-McCune-Albright fibrous dysplasia of bone. J Bone Miner Res. 2000;15:120-8.

5. Cohen MM Jr. Fibrous dysplasia is a neoplasm. Am J Med Genet. 2001;98:290-3

6. Nielsen GP, Rosenberg AE, Deshpande V, Hornicek FL, Kattapuram SV, Rosenthal DI. Diagnostic Pathology Bone: Fibrous Dysplasia. 1th ed. Canada: 2013:6-2.

7. Chapurlat RD, Meunier PJ. Fibrous dysplasia of bone. Baillieres Best Pract Res Clin Rheumatol. 2000;14:385-98.

8. Yalcinkaya U, Doganavsargil B, Sezak M, Oztop F. Craniofacial fibroosseous lesions. Türk Patoloji Dergisi. 2006;22:68-73.

9. Batista KT, Araujo HJ, Schwartzman UP. Monostotic fibrous dysplasia of the metacarpal: A case report. Rev Braz Ortop. 2016;51:730-4.

10. Ippolito E, Bray EW, Corsic A, De Maio F, Exner UG, Robey PG, Grill F, Lala R, Massobrio M, Pinggera O, Riminucci M, Snela S, Zambakidis C, Bianco P. Natural history and treatment of fibrous dysplasia of bone: A multicenter clinicopathologic study promoted by the European Pediatric Orthopaedic Society. J of Pediatr Orthop B. 2003;12:155-77.

11. Chapurlat RD, Gensburger D, Jimenez-Andrade JM, Ghilardi JR, Kelly M, Mantyh P. Pathophysiology and medical treatment of pain in fibrous dysplasia of bone. Orphanet J Rare Dis. 2012;7 Suppl $1:$ S3.
12. Faivre L, Nivelon-Chevallier A, Kottler ML, Robinet C, Khau Van Kien P, Lorcerie B, Munnich A, Maroteaux P, Cormier-Daire V, LeMerrer M. Mazabraud syndrome in two patients: Clinical overlap with McCune-Albright sndrome. Am J Med Genet. 2001;99:132-6.

13. Fitzpatrick KA, Talyanovic MS, Speer DP, Graham AR, Jacobson JA, Barnes GR, Hunter TB. Imaging findings of fibrous dysplasia with histopathologic and intraoperative correlation. AJR. 2004;182:1389-98.

14. Dorfman HD. New knowledge of fibro-osseous lesions of bone. Int J Surg Pathol. 2010;18:62-5.

15. Ruggieri P, Sim FH, Bond JR, Unni KK. Malignancies in fibrous dysplasia. Cancer. 1994;73:1411-24.

16. Doganavsargil B, Argin M, Kececi B, Sezak M, Sanli UA, Oztop F. Secondary osteosarcoma arising in fibrous dysplasia, case report. Arch OrthopTrauma Surg. 2009;129:439-44.

17. Qu N, Yao W, Cui X, Zhang H. Malignant transformation in monostotic fibrous dysplasia: Clinical features, imaging features, outcomes in 10 patients, and review. Medicine (Baltimore). 2015;94:e369.

18. Yoshida A, Ushiku T, Motoi T, Shibata T, Beppu Y, Fukayama M, Tsuda H. Immunohistchemical analysis of MDM2 and CDK4 distinguishes low-grade osteosarcoma from benign mimics. Mod Pathol. 2010;23:1279-88.

19. Dujardin F, Binh MB, Bouvier C, Gomez-Brouchet A, Larousserie F, Muret Ad, Lou1s-Brennetot C, Aurias A, Coindre JM, Guillou L, Pedeutour F, Duval H, Collin C, de Pinieux G. MDM2 and CDK4 immunohistochemistry is a valuable tool in the differential diagnosis of low-grade osteosarcomas and other primary fibroosseous lesions of the bone. Mod Pathol. 2011;24:624-37.

20. Saglik Y, Atalar H, Yildiz Y, Basarir K, Erekul S. Management of fibrous dysplasia. A report on 36 cases. Acta Orthop Belg. 2007;73:96-101.

21. Chapurlat RD. Medical therapy in adults with fibrous dysplasia of bone. J Bone Miner Res. 2006;21 Suppl 2:P114-9.

22. Li L, Hou X, Li Q, Zhang L. En bloc resection and bone graft: does it alter the natural history of monostotic expansile fibrous dysplasia in children? World J Surg Oncol. 2014;12:349.

23. Boyce AM, Burke A, Cutler Peck C, DuFresne CR, Lee JS, Collins MT. Surgical management of polyostotic craniofacial fibrous dysplasia: Long-term outcomes and predictors for postoperative regrowth. Plast Reconstr Surg. 2016;137:1833-9. 